ITC $3 / 46$

Journal of Information Technology and Control

Vol. 46 / No. 3 / 2017

pp. 293-307

DOI 10.5755/j01.itc.46.3.16766

(C) Kaunas University of Technology
A Mixed-Stable Approach to the Management of the Portfolio Using High-Frequency Financial Data

Received 2017/03/06
Accepted after revision 2017/08/04

\title{
A Mixed-Stable Approach to the Management of the Portfolio Using High-Frequency Financial Data
}

\section{Igoris Belovas}

Vilnius University, Institute of Mathematics and Informatics, Optimization Sector at Systems Analysis Department Akademijos str., 4, LT-08663 Vilnius, Lithuania

\section{Leonidas Sakalauskas}

Šiauliai University, Vilniaus str. 88, LT-76285 Šiauliai, Lithuania

\section{Vadimas Starikovičius}

Vilnius Gediminas Technical University, Laboratory of Parallel Computing

Saulètekio al. 11, LT-10223 Vilnius, Lithuania

Corresponding author: igoris.belovas@mii.vu.lt

This paper considers the problem of portfolio selection using high-frequency financial time series. Such time series often exhibit the stagnation effect when the assets' returns are not changing. This effect causes a lot of unusual difficulties in the analysis and modelling of such series. In classical statistics, when the distributional law has two first moments, i.e. mean and variance, the relationship between the two random variables is described by the covariance or correlation. However, if the financial data follow the stable law, and empirical studies often support this assumption, covariance and especially correlation often cannot be calculated. In this work, alternative relation measures are applied to deal with the portfolio selection problem using the mixed-stable modelling. The modelling is applied to the high-frequency financial time series obtained from the German DAX index intra-daily data. The performance of the mixed-stable model is compared with alternative approaches. The portfolio selection problem is formulated as the optimization problem, with covariances replaced by the generalized power-correlations. The results of the portfolio selection strategy without the relationship coefficients matrix are also presented.

KEYWORDS: financial modelling, portfolio selection, high-frequency data, mixed-stable model, generalized power-correlation. 


\section{Introduction}

The obvious wish of any financial investor is to know how to select the financial assets into a portfolio such that the expected return is maximized for a chosen level of risk. Mathematical foundation for this problem was laid by H. Markowitz in 1952 with his classical portfolio selection model [22]. It has gained a wide recognition as a basis of the modern portfolio theory. However, since its introduction, it has drawn a lot of criticism that its assumptions do not match the real financial markets. Over the years, a lot of alternative and more refined models have been proposed (see, e.g., $[7,8,9,19,20]$ and references therein).

One of the main points of criticism is that the modern portfolio theory assumes that portfolio returns are normally distributed. However, the real-world financial data often do not follow this assumption. Their behaviour is characterized by such features as skewness, kurtosis, heavy tails, self-similarity and multifractality [28, 29, 34, 35].

During the last decades numerous alternatives have been proposed: the mixture of normals by Kon (1984) [17], the compound log-normal and normal distribution by Clark (1973) [5], the mixed diffusion-jump model by Press (1967) [27], the logistic distribution by Smith (1981) [32], the scaled- $t$ distribution by Praetz (1972) [26], the exponential power distribution by Hsu (1982) [11], the normal-inverse Gaussian distribution [2] by Barndorff-Nielsen (1995), etc. Stable distribution proposed by Mandlebrot (1963) and Fama (1965) has received special attention due to its unique properties [28, 29]. A summary of the literature covering history and properties of these models is presented in $[1,31]$ and references therein.

In this work, a long time series of high-frequency financial data are considered. The performance of several aforementioned models is considered and compared with the mixed-stable model [14]. However, at this point, it needs to be noticed that although probabilistic/statistical methods are by far the most popular in the analysis of financial time series, there are other approaches as well.

The statistical approach is restricted in determining the underlying dynamics of the assets' price evolution. Some recent studies show the presence of nonlinear dependence and deterministic chaos in the real-world financial time series [23,30]. This leads to the increasing interest in an alternative approach when high-frequency financial time series are obtained from the chaotic finance systems [16, 21]. Interestingly, in a chaotic system, large and apparently random price fluctuations are caused by the internal dynamics of the system and not by external random (unpredictable) shocks.

This paper continues the research on application of stable distribution laws for modelling of financial data $[4,14]$. The main subject of this research, high-frequency financial series, often exhibit the stagnation effect when the stock prices do not change over certain periods of time. Such a behaviour is often observed for smaller companies and in developing financial markets. This effect causes a lot of unusual difficulties in the analysis and modelling of high-frequency financial time series. Mixed-stable model has been proposed to deal with this feature of modelled data (see [12]).

The application of the mixed-stable model for the analysis of large sets of high-frequency financial data and the insufficiency of the classical Gaussian as well as standard $\alpha$-stable models has been demonstrated in [14]. This approach is computationally very demanding, especially for long financial series. However, the application of parallel computing makes it both precise and practical, as it has been shown in $[3,4]$.

The main contribution of this paper is in application of mixed-stable modelling approach for the solution of portfolio selection problem. It is clear that in a financial portfolio management it is essential to determine relationships between different stock returns. According to classical statistics, the relationship between returns is described by the covariance and correlation, when the data are assumed to have finite first and second moments. However, if financial data follow the infinite-variance distribution, and empirical studies often support this assumption [31,36], the classical Markowitz portfolio selection model [22] becomes inapplicable.

In this work, the generalized Markowitz portfolio selection model is formulated by using the generalized power-correlation measures, proposed by Belovas et al. [13]. Optimal financial portfolios of nine German DAX index stocks are constructed, using the high-frequency data series and estimated parameters 
of mixed-stable models. Results of the portfolio selection strategies with and without relationship coefficients matrix are presented.

The rest of the paper is organized as follows. Section 2 presents the modelling methodology and financial data used in this study, briefly introducing stable and mixed-stable models as well as alternative approaches with finite-variance distributions. In Section 3, the performance of mixed-stable model is compared with these alternative approaches, modelling the high frequency financial data under consideration. In Section 4, the relationship (generalized power-correlation) measures are described and obtained for stocks of nine companies of German DAX index. Section 5 is devoted to the portfolio selection problem. Portfolio selection models with and without relationship coefficients matrix are formulated and results of the modelling are presented. Some conclusions are drawn in Section 6.

\section{Data and models}

In this work, the problem of portfolio selection is considered using the high-frequency trading data of nine stocks listed in German DAX index (a blue chip stock market index consisting of the 30 major German companies). Intra-daily trading data were used for the period from January 2, 2007 to December 28, 2007 with all financial transactions of corresponding stocks.

Before the analysis, raw non-homogeneous intra-daily trading data were aggregated into the equally-spaced homogeneous intra-daily time series of stock returns with different time steps. The aggregation was done with the previous-tick interpolation, since the linear interpolation relies on the future information, whereas the previous-tick interpolation is based on the information that is already known [6]. Having obtained equally-spaced price series, one can calculate the corresponding series of logarithmic returns $\left\{X_{j}\right\}: X_{j}=\ln P_{j}-\ln P_{j-1}$.

As was already discussed, the time series observed in the finance often deviate from the Gaussian model. This is also true for the high-frequency financial data [6] and the German equity market returns [10,33]. Statistical analysis performed in this study has also demonstrated that the obtained financial data series are asymmetric. The empirical kurtosis shows that the density functions of these series are more peaked than the Gaussian density functions. In Table 1, the results of such analysis are presented for high-frequency time series obtained with the time step of 16 minutes for stocks of nine DAX companies under consideration.

High-frequency financial data have some unusual properties. They can contain a high percent of observations with no price change, i.e. in a high-frequency time series, a large number of returns is equal to zero.

Table 1

Empirical moments of high-frequency series of DAX stocks returns with time step of 16 minutes

\begin{tabular}{c|l|c|c|c|c}
\hline Nr. & \multicolumn{1}{|c|}{ Company } & Mean & St. dev. & Skewness & Kurtosis \\
\hline 1 & Deutsche Bank & $-1.76 \times 10^{-5}$ & $3.08 \times 10^{-3}$ & -0.141 & 33.791 \\
\hline 2 & BASF SE & $+3.99 \times 10^{-5}$ & $2.61 \times 10^{-3}$ & 0.485 & 29.870 \\
\hline 3 & Continental AG & $-1.15 \times 10^{-6}$ & $3.20 \times 10^{-3}$ & 0.463 & 15.431 \\
\hline 4 & MAN SE & $+6.22 \times 10^{-5}$ & $3.74 \times 10^{-3}$ & 0.629 & 20.635 \\
\hline 5 & Merck KGaA & $+1.38 \times 10^{-5}$ & $3.17 \times 10^{-3}$ & 0.785 & 19.388 \\
\hline 6 & Siemens AG & $+4.60 \times 10^{-5}$ & $3.18 \times 10^{-3}$ & -0.428 & 34.202 \\
\hline 7 & Volkswagen AG & $+7.69 \times 10^{-5}$ & $2.88 \times 10^{-3}$ & 0.169 & 16.468 \\
\hline 8 & Allianz SE & $-7.32 \times 10^{-6}$ & $2.77 \times 10^{-3}$ & 0.528 & 29.442 \\
\hline 9 & Münch. Rück & $+7.82 \times 10^{-7}$ & $2.30 \times 10^{-3}$ & 0.085 & 19.470 \\
\hline
\end{tabular}


The yearly time series that are used in this study contain between two and twenty percent of zeros with the time step of 16 minutes. To deal with this stagnation effect, the mixed-stable model $[12,14]$ is employed.

Next, the stable and mixed-stable models are briefly presented for the sake of self-containment of this paper. Several alternative non-Gaussian modelling approaches are also presented to be compared with the mixed-stable model in Section 3. These alternative non-Gaussian models have finite-variance distributions. This would allow us to stay within the standard mean-variance approach [22] solving the main problem of this study, i.e. portfolio selection problem. Some studies claim that finite-variance models can outperform the stable distribution [36].

\subsection{Stable and mixed-stable models}

As is known, the probability density function of a stable distribution cannot be written analytically in general, except for a few special cases [29]. Therefore, it is usually described by its characteristic function $\varphi(t ; \alpha, \beta, \sigma, \mu)$, which depends on four parameters:

$$
\begin{aligned}
& \log \varphi(t ; \alpha, \beta, \sigma, \mu)= \\
& \left\{\begin{array}{l}
-\sigma^{\alpha}|t|^{\alpha}\left\{1-i \beta \frac{t}{|t|} \tan \frac{\pi \alpha}{2}\right\}+i \mu t, \alpha \neq 1, \\
-\sigma|t|\left\{1+i \beta \frac{2 t}{\pi|t|} \log |t|\right\}+i \mu t, \quad \alpha=1,
\end{array}\right.
\end{aligned}
$$

where $\alpha \in(0,2]$ is the stability index, $\beta \in[-1,1]$ is the skewness parameter, $\sigma>0$ is the scale parameter, $\mu \in \mathbb{R}$ is the location or shift parameter. In financial modelling it is usually observed that $\alpha>1$ [28]. More on stable distributions and their properties can be found in [29].

In this work, the maximum likelihood method [15] is used to estimate the parameters of the selected models. It is known to be the most accurate method for the evaluation of parameters of a stable model [25]. According to this method, the vector of stable parameters $\Theta=(\alpha, \beta, \mu, \sigma)$ is estimated from the set of returns $\left\{X_{k}\right\}$ by maximizing the log-likelihood function:

$$
L(\Theta)=\sum_{k=1}^{n} \ln p\left(X_{k}, \Theta\right)
$$

where

$$
\begin{gathered}
p(x, \Theta)=\frac{1}{\pi \sigma} \int_{0}^{\infty} e^{-t^{\alpha}} \cos h_{\alpha, \beta}\left(\frac{x-\mu_{0}}{\sigma}, t\right) d t, \\
h_{\alpha, \beta}(x, t)=\left\{\begin{array}{cc}
x t+\beta \tan \frac{\pi \alpha}{2}\left(t-t^{\alpha}\right), & \alpha \neq 1, \\
x t-\beta t \frac{2}{\pi} \ln t, & \alpha=1,
\end{array}\right.
\end{gathered}
$$

and

$$
\mu_{0}= \begin{cases}\mu+\beta \sigma \tan \frac{\pi \alpha}{2}, & \alpha \neq 1, \\ \mu+\beta \sigma \frac{2}{\pi} \ln \sigma, & \alpha=1 .\end{cases}
$$

Note that precise and fast calculation of $p\left(X_{k}, \Theta\right)$ values in the optimization target function (2) is a non-trivial task. In this work, the improper integral of probability density function (3) was evaluated using the methods developed and approved in previous works [3, 4].

As was already discussed, to deal with the stagnation effect in modelled data, i.e. zero returns, the mixed-stable model is employed [12]. The probability density function of a mixed-stable distribution is defined in the following way:

$$
f(x, r, \Theta)=(1-r) p(x, \Theta)+r \delta(x),
$$

where $p(x, \Theta)$ is the probability density function (3) of a $\alpha$-stable distribution (1) and $\delta(x)$ is the Dirac delta function. The new parameter $r \in(0,1)$ is the index of stagnation. See [14] for more details on the mixed-stable model and its properties.

Parameters of the mixed-stable model (6) can be estimated by maximizing the following likelihood function:

$$
l(r, \Theta)=C_{n}^{k}(1-r)^{n-k} r^{k} \prod_{j=1}^{n-k} p\left(X_{i_{j}}, \Theta\right),
$$

where $\left\{X_{i_{1}}, X_{i_{2}}, \ldots, X_{i_{n-k}}\right\}$ is a set of non-zero returns, obtained by excluding $k$ zero returns from the initial set $\left\{X_{1}, X_{2}, \ldots, X_{n}\right\}$ of returns, obtained from 
high-frequency data by the previously described procedure.

The local optimization of the first factor $(1-r)^{n-k} r^{k}$ yields $r_{\max }=\frac{k}{n}$. The optimization of the second factor in (7) is equivalent to the optimization of the log-likelihood function (2) of the stable distribution with the set $\left\{X_{i_{1}}, X_{i_{2}}, \ldots, X_{i_{n-k}}\right\}$ of non-zero returns. As in previous works $[3,4]$, the log-likelihood function (2) is optimized using the Nelder-Mead method [24]. Even though this method is not the fastest one, it is very robust and does not require any derivative (gradient, Hessian) calculation, which is problematic for the considered target function.

Next, five alternative finite-variance distributions for the modelling of stock returns are briefly presented: the mixed diffusion-jump model, the scaled- $t$ distribution, the mixture of normals distribution, the logistic distribution and the normal-inverse Gaussian distribution.

\subsection{Mixed diffusion-jump model}

A process, which mixes the Brownian motion and a compound Poisson process, was introduced by Press (1967) [27] to model the stock prices:

$$
\begin{aligned}
& d P(t)=a P(t) d t+\sigma_{D} P(t) d B(t)+ \\
& +P(t)\left(e^{Q}-1\right) d N(t) .
\end{aligned}
$$

Here $P(t)$ is the stock price, $B(t)$ is the standard Brownian motion, $N(t)$ is the homogeneous Poisson process with parameter $\lambda$. $Q$ is the normal variate with mean $\mu_{Q}$ and variance $\sigma_{Q}^{2}$.

Using Ito's lemma, one can solve the stochastic differential equation (8) for the stock return $X(t)=\ln P(t)-\ln P(t-1)$ to obtain

$$
X(t)=\mu_{D}+\sigma_{D} B(1)+\sum_{n=1}^{\Delta N(T)} Q_{n},
$$

where $\mu_{D}=a-\sigma_{D}^{2} / 2$. The probability density function for this process is given by

$$
g(x)=\sum_{n=1}^{\infty} \frac{\lambda^{n}}{n !} \frac{e^{-\lambda-\frac{\left(x-\mu_{D}-n m u\right.}{2\left(\sigma_{D}^{2}+n \sigma_{Q}^{2}\right)}}}{\sqrt{2 \pi\left(\sigma_{D}^{2}+n \sigma_{Q}^{2}\right)}} .
$$

This model has five parameters: $\lambda, \mu_{D}, \sigma_{D}, \mu_{O}, \sigma_{Q}$, which were evaluated using the maximum likelihood method. In this work, the infinite sum in definition of density function (10) was truncated up to twelve terms, what is considered accurate enough for practical purposes [31].

\subsection{Mixture of normals}

Kon (1984) [17] has proposed to use a mixture of normals to model stock returns. In this work, the mixture of two normals: $N\left(\mu_{1}, \sigma_{1}^{2}\right)$ and $N\left(\mu_{2}, \sigma_{2}^{2}\right)$ is considered with probabilities $p$ and $1-p$, accordingly. The probability density function of such mixture is given by

$$
g(x)=\frac{p}{\sigma_{1} \sqrt{2 \pi}} e^{-\frac{\left(x-\mu_{1}\right)^{2}}{2 \sigma_{1}^{2}}}+\frac{1-p}{\sigma_{2} \sqrt{2 \pi}} e^{-\frac{\left(x-\mu_{2}\right)^{2}}{2 \sigma_{2}^{2}}} .
$$

Note that this model also has five parameters: $p, \mu_{1}, \sigma_{1}$, $\mu_{2}, \sigma_{2}$, which will be evaluated using the maximum likelihood method in Section 3.

It has been reported that the mixture of exactly two normals is showing the best results in this family [36]. Note that the mixture of two normal distributions allows skewness in the data.

\subsection{Scaled- $t$ distribution}

This model was originally proposed by Praetz (1972) [26] and over the years has yearned significant recognition in modelling of stock returns [1]. The probability density function of the scaled- $t$ distribution is given by

$$
g(x)=\frac{\Gamma\left(\frac{v+1}{2}\right)}{\Gamma\left(\frac{v}{2}\right) \sqrt{\pi(v-2) \sigma^{2}}}\left(1+\frac{(x-\mu)^{2}}{(v-2) \sigma^{2}}\right)^{-\frac{v+1}{2}} .
$$

Here $\mu \in R$ is the location parameter, $\sigma>0$ is the scale parameter, and $v>2$ is the degrees of freedom parameter. This distribution is known to have heavier tails than the normal distribution. This finite-variance model has three parameters, which were evaluated by the maximum likelihood method.

\subsection{Logistic distribution}

Smith (1981) [32] has first proposed to use this distribution to model stock returns. This model was tested 
in several studies with different data [1]. The probability density function of the logistic distribution is given by

$$
g(x)=\frac{e^{\frac{x-\mu}{\sigma}}}{\sigma\left(1+e^{\frac{x-\mu}{\sigma}}\right)^{2}},
$$

where $\mu \in R$ is the location parameter and $\sigma>0$ is the scale parameter. The logistic distribution has similar shape to the normal distribution but has heavier tails (higher kurtosis). This model has only two parameters, which were evaluated by the maximum likelihood method.

\subsection{Normal-inverse Gaussian distribution}

Barndorff-Nielsen (1995) [2] has proposed to use the normal-inverse Gaussian distribution to model stock returns. The probability density function of this distribution is given by

$$
g(x)=\frac{\alpha \sigma K_{1}\left(\alpha \sqrt{\sigma^{2}+(x-\mu)^{2}}\right)}{\pi \sqrt{\sigma^{2}+(x-\mu)^{2}} e^{-\sigma \sqrt{\alpha^{2}-\beta^{2}}-\beta(x-\mu)}} .
$$

Here $K_{1}$ denotes the modified Bessel function of the third kind, $\mu \in R$ is the location (shift) parameter, $\sigma>0$ is the scale parameter. Parameter $\alpha$ describes the tail heaviness and $\beta$ is the asymmetry parameter.
The family of normal-inverse Gaussian laws is a very flexible system that includes heavy-tailed and skewed distributions. This model has four parameters, which were evaluated by the maximum likelihood method.

\section{Results of the modelling}

First, the parameters of the mixed-stable (MS) model were estimated by the maximum likelihood method for the time series of returns of nine DAX stocks, obtained from the high-frequency data with time step of 16 minutes $(\Delta t=16)$. The obtained parameters are presented in Table 2 . All these parameters were obtained using twelve digits accuracy of calculation of probability density function (3) and eight digits accuracy of maximum likelihood optimization (2).

However, there appears to be a problem when trying to test the adequacy of the constructed models. Since the mixed-stable model has a discontinuous distribution function, the classic methods, e.g. Kolmogorov-Smirnov or Anderson-Darling tests [15], cannot be applied. In this work, all constructed mixed-stable models were tested using the Koutrouvelis goodnessof-fit test [18], which is based on the empirical characteristic function. As can be seen from Table 8, none of the nine constructed models was rejected. These results provide additional trust in the descriptive power of stable laws for modelling financial data, including the high-frequency intra-daily data as in the considered case.

\section{Table 2}

ML estimates of MS parameters for DAX data series with time step $\Delta t=16 \mathrm{~min}$

\begin{tabular}{c|l|c|c|c|c|c}
\hline Nr. & \multicolumn{1}{|c|}{ Company } & $r$ & $\boldsymbol{\alpha}$ & $\boldsymbol{\beta}$ & $\boldsymbol{\mu}$ & $\boldsymbol{\sigma}$ \\
\hline 1 & Deutsche Bank & 0.025 & 1.555 & 0.028 & $-1.62 \times 10^{-6}$ & $1.32 \times 10^{-3}$ \\
\hline 2 & BASF SE & 0.031 & 1.623 & 0.083 & $+6.06 \times 10^{-5}$ & $1.30 \times 10^{-3}$ \\
\hline 3 & Continental AG & 0.027 & 1.559 & -0.018 & $-2.21 \times 10^{-5}$ & $1.50 \times 10^{-3}$ \\
\hline 4 & MAN SE & 0.023 & 1.555 & 0.035 & $+5.07 \times 10^{-5}$ & $1.71 \times 10^{-3}$ \\
\hline 5 & Merck KGaA & 0.028 & 1.588 & 0.031 & $+3.97 \times 10^{-6}$ & $1.54 \times 10^{-3}$ \\
\hline 6 & Siemens AG & 0.029 & 1.558 & 0.068 & $+7.31 \times 10^{-5}$ & $1.43 \times 10^{-3}$ \\
\hline 7 & Volkswagen AG St & 0.027 & 1.507 & 0.081 & $+9.92 \times 10^{-5}$ & $1.29 \times 10^{-3}$ \\
\hline 8 & Allianz SE & 0.021 & 1.536 & 0.001 & $-5.81 \times 10^{-7}$ & $1.21 \times 10^{-3}$ \\
\hline 9 & Münch. Rück & 0.026 & 1.603 & -0.003 & $+3.68 \times 10^{-5}$ & $1.12 \times 10^{-3}$ \\
\hline
\end{tabular}


Next, the selected models with finite-variance distributions have been tested in dealing with the considered data. Five parameters of the mixed diffusion-jump (MDJ) model were estimated by the maximum likelihood method for the time series of returns of nine DAX stocks, obtained from the high-frequency data with time step $\Delta t=16 \mathrm{~min}$. The obtained parameters are presented in Table 3. All nine constructed mixed diffusion-jump models were tested with Kolmogorov-Smirnov goodness-of-fit test. As can be seen from Table 8, all nine models were rejected, which suggests that this model in incapable of describing considered data.
Five parameters of the mixture of two normals (MN) model were estimated by the maximum likelihood method for the time series of returns of nine DAX stocks, obtained from the high-frequency data with time step $\Delta t=16 \mathrm{~min}$. The obtained parameters are presented in Table 4. All nine constructed mixture of two normals models were tested with Kolmogorov-Smirnov goodness-of-fit test. As can be seen from Table 8, all nine models were rejected.

Three parameters of the scaled- $t$ model were estimated by the maximum likelihood method for the time series of returns of nine DAX stocks, obtained from the high-frequency data with time step $\Delta t=16 \mathrm{~min}$.

\section{Table 3}

ML estimates of MDJ parameters for DAX data series with time step $\Delta t=16 \mathrm{~min}$

\begin{tabular}{c|l|c|c|c|c|c}
\hline Nr. & \multicolumn{1}{|c|}{ Company } & $\lambda$ & $\mu_{D}$ & $\sigma_{D}$ & $\mu_{Q}$ & $\sigma_{Q}$ \\
\hline 1 & Deutsche Bank & 0.120 & $-1.88 \times 10^{-5}$ & 0.002 & $+1.00 \times 10^{-5}$ & 0.007 \\
\hline 2 & BASF SE & 0.229 & $-7.88 \times 10^{-6}$ & 0.002 & $+2.05 \times 10^{-4}$ & 0.004 \\
\hline 3 & Continental AG & 0.197 & $-4.50 \times 10^{-6}$ & 0.002 & $+1.00 \times 10^{-5}$ & 0.006 \\
\hline 4 & MAN SE & 0.188 & $+9.69 \times 10^{-6}$ & 0.002 & $+1.05 \times 10^{-4}$ & 0.007 \\
\hline 5 & Merck KGaA & 0.228 & $-3.00 \times 10^{-5}$ & 0.002 & $+1.90 \times 10^{-4}$ & 0.005 \\
\hline 6 & Siemens AG & 0.192 & $+7.18 \times 10^{-6}$ & 0.002 & $+2.05 \times 10^{-4}$ & 0.006 \\
\hline 7 & Volkswagen AG St & 0.293 & $+2.30 \times 10^{-7}$ & 0.001 & $+2.60 \times 10^{-4}$ & 0.004 \\
\hline 8 & Allianz SE & 0.203 & $-2.75 \times 10^{-6}$ & 0.001 & $+4.99 \times 10^{-5}$ & 0.005 \\
\hline 9 & Münch. Rück & 0.213 & $+6.95 \times 10^{-6}$ & 0.001 & $-2.89 \times 10^{-5}$ & 0.004 \\
\hline
\end{tabular}

\section{Table 4}

ML estimates of MN parameters for DAX data series with time step $\Delta t=16 \mathrm{~min}$

\begin{tabular}{c|l|c|c|c|c|c}
\hline Nr. & \multicolumn{1}{|c|}{ Company } & $p$ & $\mu_{1}$ & $\sigma_{1}$ & $\mu_{2}$ & $\sigma_{2}$ \\
\hline 1 & Deutsche Bank & 0.087 & $-2.03 \times 10^{-5}$ & 0.009 & $-1.71 \times 10^{-5}$ & 0.002 \\
\hline 2 & BASF SE & 0.117 & $+2.79 \times 10^{-4}$ & 0.006 & $+9.75 \times 10^{-6}$ & 0.002 \\
\hline 3 & Continental AG & 0.133 & $+3.04 \times 10^{-5}$ & 0.007 & $-8.71 \times 10^{-6}$ & 0.002 \\
\hline 4 & MAN SE & 0.125 & $+4.40 \times 10^{-4}$ & 0.009 & $+1.00 \times 10^{-5}$ & 0.002 \\
\hline 5 & Merck KGaA & 0.131 & $+3.10 \times 10^{-4}$ & 0.007 & $-3.00 \times 10^{-5}$ & 0.002 \\
\hline 6 & Siemens AG & 0.117 & $+2.96 \times 10^{-4}$ & 0.008 & $+1.23 \times 10^{-5}$ & 0.002 \\
\hline 7 & Volkswagen AG St & 0.173 & $+4.00 \times 10^{-4}$ & 0.006 & $+1.00 \times 10^{-5}$ & 0.002 \\
\hline 8 & Allianz SE & 0.123 & $-1.10 \times 10^{-4}$ & 0.007 & $+7.67 \times 10^{-6}$ & 0.002 \\
\hline 9 & Münch. Rück & 0.122 & $-5.11 \times 10^{-5}$ & 0.005 & $+7.88 \times 10^{-6}$ & 0.001 \\
\hline
\end{tabular}


The obtained parameters are presented in Table 5 . The adequacy of constructed scaled- $t$ models was tested with Kolmogorov-Smirnov goodness-of-fit test. As can be seen from Table 8, scaled- $t$ models for stock returns of two DAX companies (BASF SE and Münchener Rück) were rejected. Scaled- $t$ models for seven other DAX stocks were not rejected.

Two parameters of the logistic model were estimated by the maximum likelihood method for the time series of returns of nine DAX stocks, obtained from the high-frequency data with time step $\Delta t=16 \mathrm{~min}$. The obtained parameters are presented in Table 6 . The adequacy of the constructed logistic models was tested

\section{Table 5}

ML estimates of scaled- $t$ parameters for DAX data series with time step $\Delta t=16 \mathrm{~min}$

\begin{tabular}{c|l|c|c|c}
\hline Nr. & \multicolumn{1}{|c|}{ Company } & \multicolumn{1}{c}{$\boldsymbol{\nu}$} & \multicolumn{1}{c}{$\boldsymbol{\mu}$} & \multicolumn{1}{c}{$\sigma$} \\
\hline 1 & Deutsche Bank & 2.467 & $-2.60 \times 10^{-5}$ & $3.48 \times 10^{-3}$ \\
\hline 2 & BASF SE & 2.918 & $+4.86 \times 10^{-6}$ & $2.72 \times 10^{-3}$ \\
\hline 3 & Continental AG & 2.553 & $-5.58 \times 10^{-6}$ & $3.73 \times 10^{-3}$ \\
\hline 4 & MAN SE & 2.546 & $+1.35 \times 10^{-5}$ & $4.31 \times 10^{-3}$ \\
\hline 5 & Merck KGaA & 2.710 & $-2.29 \times 10^{-5}$ & $3.50 \times 10^{-3}$ \\
\hline 6 & Siemens AG & 2.529 & $+1.00 \times 10^{-5}$ & $3.62 \times 10^{-3}$ \\
\hline 7 & Volkswagen AG St & 2.362 & $+1.93 \times 10^{-5}$ & $3.79 \times 10^{-3}$ \\
\hline 8 & Allianz SE & 2.469 & $-4.02 \times 10^{-6}$ & $3.25 \times 10^{-3}$ \\
\hline 9 & Münch. Rück & 2.791 & $+2.74 \times 10^{-6}$ & $2.47 \times 10^{-3}$ \\
\hline
\end{tabular}

with Kolmogorov-Smirnov goodness-of-fit test. As can be seen from Table 8, all nine models were rejected.

Four parameters of the normal-inverse Gaussian (NIG) model were estimated by the maximum likelihood method for the time series of returns of nine DAX stocks, obtained from the high-frequency data with time step $\Delta t=16 \mathrm{~min}$. The obtained parameters are presented in Table 7 . The adequacy of constructed normal-inverse Gaussian models was tested with Kolmogorov-Smirnov goodness-of-fit test. As can be seen from Table 8, normal-inverse Gaussian models for stock returns of five out of nine considered DAX companies were rejected.

\section{Table 6}

ML estimates of logistic parameters for DAX data series with time step $\Delta t=16 \mathrm{~min}$

\begin{tabular}{c|l|c|c}
\hline Nr. & Company & $\mu$ & $\sigma$ \\
\hline 1 & Deutsche Bank & $-1.93 \times 10^{-5}$ & $1.34 \times 10^{-3}$ \\
\hline 2 & BASF SE & $+1.97 \times 10^{-5}$ & $1.24 \times 10^{-3}$ \\
\hline 3 & Continental AG & $-8.41 \times 10^{-6}$ & $1.50 \times 10^{-3}$ \\
\hline 4 & MAN SE & $+2.53 \times 10^{-5}$ & $1.73 \times 10^{-3}$ \\
\hline 5 & Merck KGaA & $-1.32 \times 10^{-5}$ & $1.50 \times 10^{-3}$ \\
\hline 6 & Siemens AG & $+2.68 \times 10^{-5}$ & $1.44 \times 10^{-3}$ \\
\hline 7 & Volkswagen AG St & $+4.20 \times 10^{-5}$ & $1.33 \times 10^{-3}$ \\
\hline 8 & Allianz SE & $-3.61 \times 10^{-6}$ & $1.25 \times 10^{-3}$ \\
\hline 9 & Münch. Rück & $+3.26 \times 10^{-6}$ & $1.09 \times 10^{-3}$ \\
\hline
\end{tabular}

Table 7

ML estimates of NIG parameters for DAX data series with time step $\Delta t=16 \mathrm{~min}$

\begin{tabular}{c|l|c|c|c|c}
\hline Nr. & Company & $\boldsymbol{\alpha}$ & $\boldsymbol{\beta}$ & $\boldsymbol{\mu}$ & $\boldsymbol{\sigma}$ \\
\hline 1 & Deutsche Bank & 191.801 & $+2.78 \times 10^{-4}$ & $-2.85 \times 10^{-5}$ & $1.55 \times 10^{-3}$ \\
\hline 2 & BASF SE & 271.709 & $+1.76 \times 10^{-2}$ & $-2.55 \times 10^{-6}$ & $1.68 \times 10^{-3}$ \\
\hline 3 & Continental AG & 190.316 & $+8.70 \times 10^{-5}$ & $-4.71 \times 10^{-6}$ & $1.83 \times 10^{-3}$ \\
\hline 4 & MAN SE & 163.263 & $+8.06 \times 10^{-2}$ & $+1.28 \times 10^{-5}$ & $2.10 \times 10^{-3}$ \\
\hline 5 & Merck KGaA & 205.197 & $+1.08 \times 10^{-3}$ & $-2.61 \times 10^{-5}$ & $1.92 \times 10^{-3}$ \\
\hline 6 & Siemens AG & 191.320 & $+9.67 \times 10^{-4}$ & $+5.33 \times 10^{-6}$ & $1.72 \times 10^{-3}$ \\
\hline 7 & Volkswagen AG St & 194.317 & $+2.23 \times 10^{-3}$ & $+1.36 \times 10^{-5}$ & $1.53 \times 10^{-3}$ \\
\hline 8 & Allianz SE & 214.446 & $-2.80 \times 10^{-5}$ & $-6.30 \times 10^{-6}$ & $1.47 \times 10^{-3}$ \\
\hline 9 & Münch. Rück & 292.801 & $+1.46 \times 10^{-5}$ & $+1.70 \times 10^{-7}$ & $1.43 \times 10^{-3}$ \\
\hline
\end{tabular}


Table 8

Results of tests for adequacy of constructed models: '-' stands for 'rejected', '+' for 'not rejected'

\begin{tabular}{l|l|c|c|c|c|c|c}
\hline Nr. & \multicolumn{1}{|c|}{ Company } & MS & MDJ & MN & Scaled- $t$ & Log & NIG \\
\hline 1 & Deutsche Bank & + & - & - & + & - & - \\
\hline 2 & BASF SE & + & - & - & - & - & - \\
\hline 3 & Continental AG & + & - & - & + & - & + \\
\hline 4 & MAN SE & + & - & - & + & - & + \\
\hline 5 & Merck KGaA & + & - & - & + & - & - \\
\hline 6 & Siemens AG & + & - & - & + & - & - \\
\hline 7 & Volkswagen AG St & + & - & - & + & - & + \\
\hline 8 & Allianz SE & + & - & - & + & - & + \\
\hline 9 & Münch. Rück & + & - & - & - & - & - \\
\hline
\end{tabular}

The results of all tests for adequacy of constructed models with finite- and infinite-variance distributions are presented in Table 8, where ' - ' stands for 'rejected' and 't' stands for 'not rejected'. As one can see from Table 8, mixed diffusion-jump, mixture of two normals, and logistic models performed poorly dealing with the high-frequency intra-daily financial data considered in this study. Four-parameter normal-inverse Gaussian distribution described empirical data worse than three-parameter scaled- $t$ model. The latter models lead us to equivocal results. Only the mixed-stable distribution has properly described returns of all financial series. However, these results for finite- and infinite-variance distribution families call for more in-depth research with different adequacy tests and especially with diverse financial data samples (e.g. pre- and post-crash), since outliers induce heavy tails.

\section{Relationship measures}

The modern portfolio theory provides a mathematical foundation for the management of financial portfolios. It quantifies the effect of diversification, i.e. selection of various financial assets into a portfolio. Even though this effect is naturally understandable to all kinds of investors, it is difficult to model. It is clear that the performance of the portfolio selection model [22] critically depends on the correct estimation of relationship between different stocks.
In classical statistics, when the distributional law has two first moments, i.e. mean and variance, the relationship between the two random variables is described by the covariance or correlation. However, if the financial data follow the stable law, and this study supports this assumption, covariance and correlation often cannot be calculated. For the considered data, the index of stability is $1<\alpha<2$ (see Table 2) and the variance does not exist.

In this work, generalized power-correlation measures proposed by Belovas et al. [13] are employed to describe the relationship between different DAX stocks. The generalized power-correlation measure is defined as a function of two stable random variables $X$ and $Y$ :

$$
\rho_{\bullet}(X, Y)=1-\frac{E\left|\frac{X-\mu_{\bullet}(X)}{\sigma_{\bullet}(X)}-\frac{Y-\mu_{\bullet}(Y)}{\sigma_{\bullet}(Y)}\right|^{\gamma}}{E\left|\frac{X-\mu_{\bullet}(X)}{\sigma_{\bullet}(X)}\right|^{\gamma}+E\left|\frac{Y-\mu_{\bullet}(Y)}{\sigma_{\bullet}(Y)}\right|^{\gamma}},
$$

where $\gamma=\min \left(\alpha_{X}, \alpha_{Y}\right), \alpha_{X}$ and $\alpha_{Y}$ are stability indexes of random variables $X$ and $Y$, respectively, $\mu$. and $\sigma$. are standardization constants: centering and normalizing constants, respectively.

In this work, performance of three different standardizations [13] is tested for the considered data: universal standardization $\left(\rho_{U}\right)$, absolute deviation standardization $\left(\rho_{A}\right)$ and median deviation standardization $\left(\rho_{M}\right)$. 
Universal standardization. The centering and normalizing constants $\left(\mu_{U}\right.$ and $\left.\sigma_{U}\right)$ are set to be equal to the location and scale parameters of the mixed-stable model, $\mu$ and $\sigma$ from Table 2 , respectively. Note that this standardization can be applied for every possible estimate of stability index $\alpha$ and in case of $\gamma=2$ (i.e. Gaussian distribution) $\mu_{U}$ and $\sigma_{U}$ are the mean and the standard deviation, respectively.

First, using the mixed-stable models from Table 2, generalized power-correlation measures (15) of selected nine DAX stocks were calculated with the universal standardization. The obtained results (i.e. ma$\left.\operatorname{trix}\left\{\rho_{U, i j}\right\}, i, j=1, \ldots, 9\right)$ are presented in Table 9.

Absolute deviation standardization. Centering and normalizing constants ( $\mu_{A}$ and $\sigma_{A}$ respectively) are set to be equal to the mean and absolute deviation of corresponding random variables. This standardization is applicable in the case $1<\gamma<2$, i.e. when the mean exists.

Next, using the mixed-stable models from Table 2, generalized power-correlation measures (15) of selected nine DAX stocks were calculated with the absolute deviation standardization. The obtained results (i.e. matrix $\left.\left\{\rho_{A, i j}\right\}, i, j=1, \ldots, 9\right)$ are presented in Table 10.

Median deviation standardization. Centering constant $\mu_{M}$ is set to be equal to the median of the corresponding random variable. Normalizing constant $\sigma_{M}$ is set to be equal to the median of absolute deviation of the corresponding random variable. This standardization is also applicable in the case $\gamma<1$, i.e. when the mean does not exist.

Finally, using the mixed-stable models from Table 2, generalized power-correlation measures (15) of selected nine DAX stocks were calculated with the median deviation standardization. The obtained results (i.e. matrix $\left.\left\{\rho_{M, i j}\right\}, i, j=1, \ldots, 9\right)$ are presented in Table 11.

As Tables 9-11 indicate, all three standardizations are producing very similar results for the considered data. The differences between obtained matrices of generalized power-correlation measures are small (in the third significant digit):

$$
\begin{aligned}
& \left\|\left\{\rho_{U, i j}\right\}-\left\{\rho_{A, i j}\right\}\right\|_{\max }=2.208 \times 10^{-3} \\
& \left\|\left\{\rho_{U, i j}\right\}-\left\{\rho_{M, i j}\right\}\right\|_{\max }=7.447 \times 10^{-4} \\
& \left\|\left\{\rho_{A, i j}\right\}-\left\{\rho_{M, i j}\right\}\right\|_{\max }=2.195 \times 10^{-3}
\end{aligned}
$$

Similarly to the Pearson correlation coefficient, the generalized power-correlation measure (15) indicates the strength of a linear dependence between the two random variables. However, in the general statistical practice, both coefficients are used to indicate the departure of two variables from independence.

\section{Table 9}

Generalized power-correlation measures with universal standardization

\begin{tabular}{c|l|l|l|l|l|l|l|l|l|l}
\hline Nr. & \multicolumn{1}{|c|}{ Company } & DB & BASF & CAG & MAN & Merck & SAG & VW & ASE & MR \\
\hline 1 & Deutsche Bank & 1.000 & 0.430 & 0.396 & 0.425 & 0.286 & 0.444 & 0.335 & 0.534 & 0.512 \\
\hline 2 & BASF SE & 0.430 & 1.000 & 0.359 & 0.384 & 0.291 & 0.385 & 0.309 & 0.429 & 0.450 \\
\hline 3 & Continental AG & 0.396 & 0.359 & 1.000 & 0.399 & 0.278 & 0.357 & 0.353 & 0.399 & 0.386 \\
\hline 4 & MAN SE & 0.425 & 0.384 & 0.399 & 1.000 & 0.281 & 0.415 & 0.327 & 0.397 & 0.385 \\
\hline 5 & Merck KGaA & 0.286 & 0.291 & 0.278 & 0.281 & 1.000 & 0.292 & 0.232 & 0.281 & 0.286 \\
\hline 6 & Siemens AG & 0.444 & 0.385 & 0.357 & 0.415 & 0.292 & 1.000 & 0.290 & 0.431 & 0.411 \\
\hline 7 & Volkswagen AG St & 0.335 & 0.309 & 0.353 & 0.327 & 0.232 & 0.290 & 1.000 & 0.329 & 0.322 \\
\hline 8 & Allianz SE & 0.534 & 0.429 & 0.399 & 0.397 & 0.281 & 0.431 & 0.329 & 1.000 & 0.568 \\
\hline 9 & Münch. Rück & 0.512 & 0.450 & 0.386 & 0.385 & 0.286 & 0.411 & 0.322 & 0.568 & 1.000 \\
\hline
\end{tabular}




\section{Table 10}

Generalized power-correlation measures with absolute deviation standardization

\begin{tabular}{c|l|l|l|l|l|l|l|l|l|l}
\hline Nr. & Company & DB & BASF & CAG & MAN & Merck & SAG & VW & ASE & MR \\
\hline 1 & Deutsche Bank & 1.000 & 0.432 & 0.396 & 0.425 & 0.287 & 0.445 & 0.335 & 0.534 & 0.514 \\
\hline 2 & BASF SE & 0.432 & 1.000 & 0.359 & 0.384 & 0.291 & 0.386 & 0.310 & 0.431 & 0.450 \\
\hline 3 & Continental AG & 0.396 & 0.359 & 1.000 & 0.399 & 0.278 & 0.357 & 0.353 & 0.399 & 0.386 \\
\hline 4 & MAN SE & 0.425 & 0.384 & 0.399 & 1.000 & 0.282 & 0.415 & 0.327 & 0.397 & 0.385 \\
\hline 5 & Merck KGaA & 0.287 & 0.291 & 0.278 & 0.282 & 1.000 & 0.293 & 0.233 & 0.282 & 0.286 \\
\hline 6 & Siemens AG & 0.445 & 0.386 & 0.357 & 0.415 & 0.293 & 1.000 & 0.289 & 0.431 & 0.412 \\
\hline 7 & Volkswagen AG St & 0.335 & 0.310 & 0.353 & 0.327 & 0.233 & 0.289 & 1.000 & 0.329 & 0.322 \\
\hline 8 & Allianz SE & 0.534 & 0.431 & 0.399 & 0.397 & 0.282 & 0.431 & 0.329 & 1.000 & 0.570 \\
\hline 9 & Münch. Rück & 0.514 & 0.450 & 0.386 & 0.385 & 0.286 & 0.412 & 0.322 & 0.570 & 1.000 \\
\hline
\end{tabular}

\section{Table 11}

Generalized power-correlation measures with median deviation standardization

\begin{tabular}{c|l|c|c|c|c|c|c|c|c|c}
\hline Nr. & \multicolumn{1}{|c|}{ Company } & DB & BASF & CAG & MAN & Merck & SAG & Vw & ASE & MR \\
\hline 1 & Deutsche Bank & 1.000 & 0.430 & 0.396 & 0.425 & 0.287 & 0.444 & 0.335 & 0.534 & 0.512 \\
\hline 2 & BASF SE & 0.430 & 1.000 & 0.359 & 0.384 & 0.291 & 0.385 & 0.309 & 0.430 & 0.450 \\
\hline 3 & Continental AG & 0.396 & 0.359 & 1.000 & 0.399 & 0.278 & 0.357 & 0.353 & 0.399 & 0.385 \\
\hline 4 & MAN SE & 0.425 & 0.384 & 0.399 & 1.000 & 0.282 & 0.415 & 0.327 & 0.396 & 0.385 \\
\hline 5 & Merck KGaA & 0.287 & 0.291 & 0.278 & 0.282 & 1.000 & 0.292 & 0.232 & 0.282 & 0.286 \\
\hline 6 & Siemens AG & 0.444 & 0.385 & 0.357 & 0.415 & 0.292 & 1.000 & 0.289 & 0.431 & 0.412 \\
\hline 7 & Volkswagen AG St & 0.335 & 0.309 & 0.353 & 0.327 & 0.232 & 0.289 & 1.000 & 0.329 & 0.322 \\
\hline 8 & Allianz SE & 0.534 & 0.430 & 0.399 & 0.396 & 0.282 & 0.431 & 0.329 & 1.000 & 0.568 \\
\hline 9 & Münch. Rück & 0.512 & 0.450 & 0.385 & 0.385 & 0.286 & 0.412 & 0.322 & 0.568 & 1.000 \\
\hline
\end{tabular}

To test the significance of the obtained relationship measures $\rho_{i j}$, the following bootstrap algorithm is employed:

1 Generate a pair of mixed-stable series for the $i^{\text {th }}$ and $j^{\text {th }}$ stocks using estimated parameters from Table 2.

2 Calculate the $k^{\text {th }}$ value of relation measure $\rho_{i j}^{k}$ between generated series.

3 Repeat steps 1 and 2 for $k=1 \ldots N$ and construct the ordered series of estimates $\rho_{i j}^{(k)}$.
4 Check the $95 \%$ confidence interval for $\rho_{i j}$ spanning from the $2.5^{\text {th }}$ to the $97.5^{\text {th }}$ percentile of the resampled $\rho_{i j}^{k}$ values.

\section{Portfolio selection}

High-frequency financial data considered in this study follow the infinite-variance distribution. Hence, the classical Markowitz portfolio selection 
model [22] is inapplicable. Next, two strategies for portfolio selection are formulated and considered.

\subsection{The portfolio selection strategy with the relationship coefficients matrix}

For the considered data, the portfolio selection problem can be formulated as a generalized Markowitz optimization problem [19] replacing the covariance matrix by the matrix of generalized power-correlation measures (15):

$$
\min _{\sum \omega_{i}=1}\left((1-\lambda) \sum_{i=1}^{n} \sum_{j=1}^{n} \omega_{i} \omega_{j} \rho_{i j}-\lambda \sum_{i=1}^{n} \omega_{i} \mu_{i}\right)
$$

where $\omega_{i} \geq 0$ is the weight of the $i^{\text {th }}$ equity in the portfolio, $\mu_{i}$ is the location parameter (expected return of the $i^{\text {th }}$ equity), $\rho_{i j}$ is the relationship measure between the $i^{\text {th }}$ and $j^{\text {th }}$ equities (generalized power-correlation), and $\lambda \in[0,1]$ is the optimization constant (risk tolerance factor). The first constituent of this objective function characterizes the risk of portfolio (portfolio return variance), while the second one defines the expected return of portfolio.

The optimization problem (17) was solved with $\lambda=\frac{1}{2}$. The optimal portfolios were obtained for all the three relationship matrices of generalized power-correlation measures with universal, absolute deviation and median deviation standardizations (see Tables 9-11). The obtained optimal weights are presented in Table 12.

\section{Table 12}

Optimal portfolios constructed with and without relationship coefficients

\begin{tabular}{c|l|c|c|c|c}
\hline Nr. & \multicolumn{1}{|c|}{ Company } & $\omega_{i}^{U}$ & $\omega_{i}^{A}$ & $\omega_{i}^{M}$ & $\omega_{i}$ \\
\hline 1 & Deutsche Bank & 0.055 & 0.054 & 0.055 & 0.000 \\
\hline 2 & BASF SE & 0.106 & 0.106 & 0.106 & 0.195 \\
\hline 3 & Continental AG & 0.113 & 0.113 & 0.113 & 0.034 \\
\hline 4 & MAN SE & 0.103 & 0.103 & 0.102 & 0.000 \\
\hline 5 & Merck KGaA & 0.207 & 0.207 & 0.207 & 0.139 \\
\hline 6 & Siemens AG & 0.109 & 0.110 & 0.109 & 0.108 \\
\hline 7 & Volkswagen AG St & 0.177 & 0.177 & 0.177 & 0.218 \\
\hline 8 & Allianz SE & 0.060 & 0.060 & 0.060 & 0.044 \\
\hline 9 & Münch. Rück & 0.070 & 0.070 & 0.070 & 0.260 \\
\hline
\end{tabular}

As can be expected from the small differences in the relationship matrices, differences between the optimal weights are also very small. As can be seen from Table 12, the choice of standardization is not significant for the data considered in this study. However, this issue is still worth further investigation.

\subsection{The portfolio selection strategy without the relationship coefficients matrix}

The portfolio selection problem can be formulated without the relationship matrix. In the case of stable distribution, the portfolio selection problem may be formulated with the following objective function [28]:

$F(\vec{\omega})=\frac{1}{\gamma}\left(\frac{1}{N} \sum_{j=1}^{N}\left|\sum_{i=1}^{n} \omega_{i}\left(X_{j i}-\mu_{i}\right)\right|^{\gamma}\right)^{\frac{1}{\gamma}}-\sum_{i=1}^{n} \omega_{i} \mu_{i}$,

where $\vec{\omega}=\left(\omega_{1,}, \ldots, \omega_{n}\right)$ is the vector of weights of stocks in the portfolio, $X_{j i}$ is the return of the $i^{\text {th }}$ stock at the $j^{\text {th }}$ time moment, $\gamma=\min _{i=1}\left\{\alpha_{i}\right\}, \alpha_{i}$ and $\mu_{i}$ are the stability index and location parameter of stable model of the $i^{\text {th }}$ stock, respectively.

To find an optimal portfolio the following optimization problem must be solved:

$\min _{\sum \omega_{i}=1, \quad \omega_{i} \geq 0} F(\vec{\omega})$

Adding the constraint $\sum_{i=1}^{n} \omega_{i} \mu_{i}=\mu_{P}$ to (17) and (19), one will obtain portfolios with a fixed return $\mu_{P}$.

In this work, the optimization problem (19) was solved using the high-frequency data of nine DAX stocks. Obtained optimal weights are presented in the last column of Table 12. A noticeably different structure of the portfolio was obtained if comparing to the solutions of the problem (17). Interestingly, some stocks were actually excluded from the optimal portfolio.

\section{Conclusions}

Historically, Gaussian models were applied to the portfolio optimization problem for a long time. However, it has been shown many times in various studies that the stock price returns often do not follow the 
Gaussian distribution. Therefore, over the years, a number of alternative approaches has been proposed. In this paper, the descriptive power of $\alpha$-stable laws was re-examined modelling the high-frequency trading data of nine German DAX index stocks. The results of the performed tests have demonstrated the indisputable advantage of stable models against the five rival models (mixed diffusion-jump, mixture of two normals, the scaled- $t$, logistic and normal-inverse Gaussian distributions).

While constructing an optimal portfolio, it is critically important to determine the possible relationships between different stock returns. However, if the financial data follow the stable law, classical relationship measures (covariance, correlation) cannot be applied because the second moment does not exist. In this paper, the generalized Markowitz problem is formulated and solved replacing the covariance matrix by the matrix of generalized power-correlation

\section{References}

1. Aparicio, F., Estrada, J. Empirical Distributions of Stock Returns: Scandinavian Securities Markets, 199095. Statistics and Econometrics Series, 1996, 25, 1-14.

2. Barndorff-Nielsen, O. E. Normal Inverse Gaussian Distributions and the Modeling of Stock Returns. Research Report, Department of Theoretical Statistics, Aarhus University, 1995.

3. Belovas, I., Starikovičius, V. Parallelization of $\alpha$-Stable Modelling Algorithms. Mathematical Modelling and Analysis, 2007, 12(4), 409-418. https://doi. org/10.3846/1392-6292.2007.12.409-418

4. Belovas, I., Starikovičius, V. Parallel Computing for Mixed-Stable Modelling of Large Data Sets. Information Technology and Control, 2015, 44(2), 148-154. https://doi.org/10.5755/j01.itc.44.2.6723

5. Clark, P. K. A Subordinated Stochastic Process Model with Finite Variance for Speculative Prices. Econometrica,1973,41,135-155.https://doi.org/10.23077/1913889

6. Dacorogna, R., Gençay, U., Müller, A., Olsen, R., Pictet, O. An Introduction of High-Frequency Finance. Academic Press, San Diego, 2001.

7. Elton, E. J., Gruber, M. J. Modern Portfolio Theory and Investment Analysis. John Wiley \& Sons, New York, 1995. measures. Three generalized power-correlation measures with universal, absolute deviation and median deviation standardizations showed very close results. An alternative formulation of the portfolio selection problem without the relationship matrix was also formulated and solved. It has produced interesting results with an essentially different structure of the portfolio. Such results encourage further research on application of stable modelling approach for financial portfolio management.

\section{Acknowledgements}

Authors would like to thank the anonymous reviewer for careful reading of the manuscript and providing constructive comments and suggestions, which have helped them to improve the quality of the paper.

8. Hatemi, A., El-Khatib, Y. Portfolio Selection: An Alternative Approach. Economics Letters, 2015, 135, 141143. https://doi.org/10.1016/j.econlet.2015.08.021

9. Hitaj, A., Mercuri, L., Rroji, E. Portfolio Selection with Independent Component Analysis. Finance Research Letters, 2015, 15, 146-159. https://doi.org/10.1016/j. frl.2015.09.005

10. Hoechstoetter, M., Rachev, S., Fabozzi, F. J. Distributional Analysis of the Stocks Comprising the DAX 30. Probability and Mathematical Statistics, 2005, 25(2), 363-383.

11. Hsu, D. A Bayesian Robust Detection of Shift in the Risk Structure of Stock Market Returns. Journal of the American Statistical Association, 1982, 777(377), 29-39. https://doi.org/10.1080/01621459.1982.104777763

12. Kabašinskas, A., Rachev, S., Sakalauskas, L., Sun, W., Belovas, I. $\alpha$-Stable Paradigm in Financial Markets. Journal of Computational Analysis and Applications, 2009, 11(3), 642-688.

13. Kabašinskas, A., Rachev, S., Sakalauskas, L., Sun, W., Belovas, I. Stable Mixture Model with Dependent States for Financial Return Series Exhibiting Short Histories and Periods of Strong Passivity. Journal of Computational Analysis and Applications, 2010, 12(N1-B), 268-292. 
14. Kabašinskas, A., Sakalauskas, L., Sun, W., Belovas, I. Mixed-Stable Models for Analyzing High-Frequency Financial Data. Journal of Computational Analysis and Applications, 2012, 14(7), 1210-1226.

15. Kendall, M., Stuart, A. The Advanced Theory of Statistics. London, Griffin, Vol. 2, $196 \%$.

16. Kocamaz, U. E., Goksu, A., Taskin, H., Uyaroglu, Y. Synchronization of Chaos in Nonlinear Finance System by Means of Sliding Mode and Passive Control Methods: A Comparative Study. Information Technology and Control, 2015, 44(2), 172-181. https://doi.org/10.5755/j01. itc. 44.2 .7732

17. Kon, S. Model of Stock Returns - A Comparison. Journal of Finance, 1984, 39(1), 147-165.

18. Koutrouvelis, I., Kellermeier, J. Goodness-of-Fit Test Based on the Empirical Characteristic Function when Parameters Must Be Estimated. Journal of the Royal Statistical Society, Series B (Methodological), 1981, 43(2), 173-176.

19. Krokhmal, P., Uryasev, S., Palmquist, J. Portfolio Optimization with Conditional Value-at-Risk Objective and Constraints. The Journal of Risk, 2001, 4(2), 43-68. https://doi.org/10.21314/JOR.2002.057

20. Low, R. K. Y., Faff, R., Aas, K. Enhancing Mean-Variance Portfolio Selection by Modeling Distributional Asymmetries. Journal of Economics and Business, 2016, 85, 49-72. https://doi.org/10.1016/j.jeconbus.2016.01.003

21. Ma, J. H., Chen, Y. S. Study for the Bifurcation Topological Structure and the Global Complicated Character of a Kind of Nonlinear Finance System (I). Applied Mathematics and Mechanics, 2001, 22(11), 1240-1251. https://doi.org/10.1023/A:1016313804297

22. Markowitz, H. Portfolio Selection. Journal of Finance, 1952, 7(1), 77-91.

23. Mishra, R. K., Sehgal, S., Bhanumurthy, N. R. A Search for Long-Range Dependence and Chaotic Structure in Indian Stock Market. Review of Financial Economics, 2011, 20, 96-104. https://doi.org/10.1016/j. rfe.2011.04.002

24. Nelder, J., Mead, R. A Simplex Method for Function Minimization. Computer Journal, 1965, 7, 308-313. https:// doi.org/10.1093/comjnl/r.4.308
25. Ojeda, D. Comparative Study of Stable Parameter Estimators and Regression with Stably Distributed Errors. PhD thesis, American University, 2001.

26. Praetz, P. The Distribution of Share Price Changes. Journal of Business, 1972, 45, 49-55. https://doi. org/10.1086/295425

27. Press, S. J. A Compound Events Models of Security Prices. Journal of Business, 1967, 40, 317-335. https://doi. org/10.1086/294980

28. Rachev, S., Mittnik, S. Stable Paretian Models in Finance. John Wiley \& Sons, New York, 2002.

29. Samorodnitsky, G., Taqqu, M. Stable Non-Gaussian Random Processes, Stochastic Models with Infinite Variance. Chapman \& Hall, New York - London, 2000.

30. Sarkar, A., Chakrabarti, G., Sen, C. Volatility, Long Memory, and Chaos: A Discussion on Some "Stylized Facts" in Financial Markets with a Focus on High Frequency Data. In: Development and Sustainability: India in a Global Perspective, Springer India, 2013, 71-101.

31. Shao, Q., Yu, H., Yu, J. Do Stock Returns Follow a Finite Variance Distribution? Annals of Economics and Finance, 2001, 2, 467-486.

32. Smith, J. The Probability Distribution of Market Returns: A Logistic Hypothesis. PhD thesis, University of Utah, 1981.

33. Sun, W., Rachev, S., Fabozzi, F. Fractals or I. I. D.: Evidence of Long-Range Dependence and Heavy Tailedness from Modeling German Equity Market Returns. Journal of Economics and Business, 2007, 59(6), 575595. https://doi.org/10.1016/j.jeconbus.2007.02.001

34. Sun, W., Rachev, S., Fabozzi, F. Long-Range Dependence, Fractal Processes, and Intra-Daily Data. In: Handbook of IT and Finance, Springer, 2008, 543-586. https://doi.org/10.1007/978-3-540-49487-4_23

35. Tokat, Y., Rachev, S., Schwartz, E. The Stable Non-Gaussian Asset Allocation: A Comparison with the Classical Gaussian Approach. Journal of Economic Dynamics \& Control, 2003, 27, 937-969. https://doi.org/10.1016/ S0165-1889(02)00050-7

36. Tucker, A. A Reexamination of Finite- and Infinite-Variance Distributions as Models of Daily Stock Returns. Journal of Business and Economic Statistics, 1992, 10, 73-81. 


\section{Summary / Santrauka}

This paper considers the problem of portfolio selection using high-frequency financial time series. Such time series often exhibit the stagnation effect when the assets' returns are not changing. This effect causes a lot of unusual difficulties in the analysis and modelling of such series. In classical statistics, when the distributional law has two first moments, i.e. mean and variance, the relationship between the two random variables is described by the covariance or correlation. However, if the financial data follow the stable law, and empirical studies often support this assumption, covariance and especially correlation often cannot be calculated. In this work, alternative relation measures are applied to deal with the portfolio selection problem using the mixed-stable modelling. The modelling is applied to the high-frequency financial time series obtained from the German DAX index intra-daily data. The performance of the mixed-stable model is compared with alternative approaches. The portfolio selection problem is formulated as the optimization problem, with covariances replaced by the generalized power-correlations. The results of the portfolio selection strategy without the relationship coefficients matrix are also presented.

Straipsnyje nagrinėjamas vertybinių popierių portfelio sudarymo uždavinys panaudojant didelio dažnio akcijų grąžų laiko eilutes. Tokiose laiko eilutèse dažnai stebimas stagnacijos efektas, kai akcijos kaina nesikeičia ir eilutėje gaunamos nulinès grąžos. Šis efektas sukelia neįprastas problemas tokių laiko eilučių analizèje ir modeliavime.

Sudarant vertybinių popierių portfelį, labai svarbu yra tinkamai įvertinti ryšį tarp atskirų akcijų grąžų. Klasikinejje statistinëje analizèje, kai tikimybinis skirtinis turi pirmuosius du momentus, sąrš̌is tarp dviejų atsitiktinių dydžių aprašomas kovariacijos ir koreliacijos koeficiento pagalba. Tačiau, kai duomenis yra pasiskirstę pagal stabilujį dèsnį, o empirinių finansinių duomenų tyrimai dažnai patvirtina tokią prielaidą, dispersija, o kai kada ir vidurkis, neegzistuoja.

Darbe yra sudaromi mišrūs-stabilūs modeliai didelio dažnio akcijų grąžų laiko eilutèms, gautoms iš prekybos biržoje duomenų devynioms Vokietijos akcijų indekso DAX įmonèms. Sudaryti mišrieji-stabilieji modeliai yra palyginami su alternatyviais modeliais, turinčiais baigtinę dispersiją.

Vertybinių popieriu portfelio sudarymo uždavinys yra formuluojamas kaip optimizacijos uždavinys kovariacijos matricą pakeičiant matrica su apibendrintais ryšio stiprumo matais. Kartu nagrinejjama kita portfelio sudarymo strategija, kai optimizacijos uždavinys sudaromas be akcijų sąryšių matricos. 